It will be remembered that the British Medical Association appointed a committee to consider fractures, and that this committee issued its report in February last. Referring to the subject of physiotherapy that report states :

“ Excellent primary treatment is of little avail in many fractures unless it is followed by a phase of active exercise directed to a complete restoration of function ; it is this latter phase which is so commonly absent. 'This remedial treatment must be primarily active in nature, concentrating on the performance of tasks rather than passive submission to massage. The committee believes that .. massage staffs should concentrate on securing the active co-operation of the patient, and on teaching, stimulating, and encouraging him to undertake his own remedial exercise."

Most orthopaedic surgeons will be in agreement with this statement, and I think it may be taken for granted that physiotherapy has a definite part in the treatment of injuries. The essential point, however, is to ensure that it is used to the greatest advantage.

Success in the treatment of fractures, and indeed of all injuries, depends to a large extent on continuity of treatment of each individual case. On this matter the B.M.A. report states :

"As a rule, on leaving the ward the patient is referred to a massage department under the charge of a different officer, who has taken no share in the earlier treatment. Union of the fracture is thus the signal for a complete break in the continuity of treatment; those responsible for the initial treatment do not know the end-results of their cases; and those who see the end-results do not know how the cases were treated in the early stages. There is no one individual to follow the case from start to finish and to feel pride or disappointment in the final result."

This, of course, applies equally to out-patient cases and to injuries which are referred to a special and independent physiotherapy department.

\section{Continuity of Treatment}

If continuity of treatment is so essential to success the question may naturally be asked whether physiotherapy can be applied without interfering with this principle. Now it is quite clear that this is possible. There are three obvious methods, any one of which, if adopted, would preserve this principle:

1. The physiotherapy department should be under the charge of the surgeon responsible for the traumatic surgery of the hospital.

2. The officer in charge of the physiotherapy department should be a member of the team dealing with all traumatic cases.

3. An appropriate number of masseuses should be detached from the ordinary work of the physiotherapy department to be responsible to, and under the control of, the surgeon in charge of these cases.

By adopting one of these methods that common cause of wasted effort, divided responsibility, would be avoided.

Continuity of treatment in my view, however, includes certain additional factors, and of these the most important are a careful selection of cases and regular re-examination by the surgeon responsible. There is no doubt that physiotherapy has sometimes come into disrepute because these factors have not been carefully provided for. For example, a man with a stiff finger needing either amputation or other operative treatment is sometimes advised and given physiotherapy although there is no possibility of achieving any result. A careful selection of cases would prevent this from occurring. Patients sometimes undergo treatment in a physiotherapy department for long periods without re-examination, and as a result they become hospitalized; not only do they not improve, but they reach such a state of mind as almost to prevent further improvement. This would be avoided by regular re-examination.

\section{Rehabilitation}

It will be remembered that during the war workshops were attached to most military orthopaedic hospitals, where men who were not able to return to civilian life could undertake useful and interesting work, thus improving their physical condition and preventing that degeneration of morale which so often accompanies lack of employment. In civilian life the man who is certiried to be fit for light work, and who is engaged in an industry in which it is impossible to provide this, is placed in a very difficult position. For this type of case rehabilitation centres corresponding to the war workshops are urgently needed. They would enable a man to regain his full working capacity as soon as possible, and if they could be established and conducted in conjunction with physiotherapy departments they would be of great value.

\section{Summary}

My conclusion is that physiotherapy, particularly that aiming at re-education, has a most important part to play in the treatment of injuries. It should be arranged, however, so that there is no interference with continuity of treatment, and it should be carefully supervised. In many cases its usefulness would be increased by association with. a rehabilitation workshop.

\section{POTASSIUM PERMANGANATE POISONING}

BY

\author{
Stanley G. WILlimotT, Ph.D.Cantab., B.Sc. \\ Ph.D.LiverP. \\ GOVERNMENT ANALYST, CYPRUS \\ AND
}

MARK FREIMAN, M.D.

MEDICAL OFFICER, CYPRUS AND GENERAL ASBESTOS COMPANY

Potassium permanganate is so widely used and readily obtained that its toxic properties are easily overlooked. In England fatal cases of poisoning are fortunately rare, but not a few cases, some fatal, have been reported from the Continent. Popper ${ }^{1}$ has recorded twenty-six authenticated cases of poisoning, the majority among women suicides. Starkenstein ${ }^{2}$ reported a single case in which death occurred from complications, while Leschke ${ }^{3}$ mentions two cases, in one of which death occurred from syncope following the ingestion of a dose of 15 to 20 grams of the pure crystals. Three cases are recorded in English toxicological literature, including the non-fatal case of Hawthorne, ${ }^{4}$ where apparently 22 grains (1.43 grams) were ingested as pills. In yet another case ${ }^{5} 15$ to 20 grams of permanganate dissolved in water were taken ; heart symptoms developed, but recovery followed treatment by gastric lavage and the administration of a cardiac tonic.

In Cyprus at least one case of attempted suicide, by a European woman, occurred in 1933, although there were probably others unknown to the authorities. In this case a strong solution of potassium permanganate was taken in unknown amount. The patient showed the usual symptoms of this type of poisoning, but after four days' treatment in hospital made a complete and uneventful recovery. In all these cases the poison was taken by the mouth, either in the form of pills, crystals, or a concentrated solution, but the fatal dose, which presumably must be large, is not known. After ingestion 
the poison attacks particularly the heart, the circulation, and the central nervous system.

The signs and symptoms of acute potassium permanganate poisoning have been well described in $v i v o^{2}{ }^{3}$ and post mortem, 4 so that little need be said here. It is interesting to note, however, that in severe cases, such as that of Box, ${ }^{4}$ the destruction of tissue was so extensive as to suggest an alkali corrosive. Nevertheless, the burns produced by potassium permanganate and their sequelae show important differences from those of the caustic alkalis which were recently described by one of us. ${ }^{6}$

\section{Medicinal Uses of Permanganate}

Potassium permanganate is the only official salt of manganese, the B.P. dose of which is 1 to 3 grains $(0.06$ to $0.2 \mathrm{gram})$, and it is not included in any schedule of poisons. By reason of its oxidizing action in acid or alkaline solution it is valued for its disinfectant, deodorant, and germicidal properties. In dilute solution it is a safe internai as well as external disinfectant, as is shown by its being utilized for washing out the stomach in cases of poisoning by alkaloids (especially morphine and opium) and by cyanides. In the solid state it is an effective local remedy in all kinds of snakebite, if applied immediately; its use in very dilute solution as a gargle, mouth wash, and for vaginal injection, and in stronger concentration for urethral irrigation in gonorrhoea, is well-accepted practice. In the lastnamed condition, according to Burke, ${ }^{5}$ irrigation with permanganate of no definite strength was practised during the war, since the urethra gradually acquires toleration to it. Here the time factor and the concentration are evidently the most important considerations. Potassium permanganate also posscsses anaesthetic action on the genito-urinary mucous membranes, and solutions of 1 in 5,000 have been employed for producing transitory anaesthesia of the urethra, thereby allowing the painless passage of sounds. ${ }^{\text {? }}$

\section{Toxic Actions}

Although one of the safest disinfectants when used in proper strength, it is easy to overlook the fact that potassium permanganate possesses a definite though low toxicity. Even dilute solutions may cause irritation to the stomach, while concentrated solutions inflame the mucous membrane, and may even induce gastro-enteritis (Dixon). ${ }^{8}$ It is also within our experience that, following a vaginal injection of a strong solution of permanganate in error, abortion has resulted in early pregnancy. Other experiences have shown that, although not a corrosive, potassium permanganate, as a solid or in concentrated solution acts as a severe irritant. The toxic effects of potash salts on the heart muscle and the central nervous system have been ascribed by pharmacologists to the $K$ ion, and this would seem to be the case with potassium permanganate.

\section{Record of Case}

The distinguishing feature in the case reported here was that the permanganate was not ingested per os, but was self-injected through the urethral canal, the total amount of solution brought in contact with the tissues of the urethra and bladder being not less than $200 \mathrm{c} . \mathrm{cm}$. of a 10 per cent. solution, equivalent to 20 grams of the solid salt.

A mechanic in an asbestos mine, aged 23, had sexual relations and became afraid of infection. Hearing that irrigation of the urethra with permanganate solution was a preventive against gonorrhoea, he bought 25 grams of the crystals and carefully dissolved the whole amount in a teacupful of water. $\mathrm{He}$ then proceeded to make urethral irrigations by means of a smail rectal syringe. After the first three irrigations during the morning of February 24th he experienced a severe burning sensation in the urethra and difficulty in passing urine. In spite of these symptoms he continued the irrigations throughout the next day, and was finally brought to hospital as a stretcher case on February 26th.

The patient ras in a state of severe shock, though fully conscious, but the voice was aphonic. The skin was pale, and the mucous membranes were livid. There was considerable sweating, the pulse rate was 120 , and the temperature was $98.8^{\circ} \mathrm{F}$. The knees were drawn up to the abdomen, and movements of the lower limbs caused severe pain in the abdominal area, which was soft and presented some défense musculaire in the pelvic region. The bladder was palpable and distended up to the navel; urine could not be passed. The heart showed signs of acute weakness, and the respiration was quickened to 36 . The spleen was enlarged by chronic malaria. The pain in the bladder was so severe that repeated injections with morphine gave no relief.

A. No. 2 catheter was introduced, through which passed $1,350 \mathrm{c.cm}$. of sanguineous urine, which contained nucleoprotein and numerous red cells interspersed with a few white. By the evening of the same day the temperature had increased to $103.8^{\circ} \mathrm{F}$., and signs of peritonitis appeared. Next morning the temperature was $101^{\circ} \mathrm{F}$., but it rose again to $103.8^{\circ} \mathrm{F}$. in the afternoon, and death ensued at 8.30 p.m. the same day, four days from the time the permanganate irrigations began. During the two days of observed illness the frequency of the pulse was never less than 118, and a few hours before death it rose to the exceptional figure of 180 per minute.

At the post-mortem examination next morning there were no unusual external appearances, and rigor mortis was present in all parts. Slight oedema of both lungs was noted, and the liver was apparently normal; the spleen was hard and enlarged to about twice the normal size, and both kidneys showed some enlargement. Ascending from the bladder to the umbilicus there was adhesive peritonitis, and the bladder was much distended, hyperaemic, and acutely inflamed, its walls being hard and devoid of elasticity. It contained $200 \mathrm{c} . \mathrm{cm}$. of sanguineous urine. On the mucous membrane there were burns ranging in size from a pinpoint to a half-crown; they occurred especially near the urethral orifice, and to some extent in the urethra. The mucous membrane was reddish brown, scorched in parts, and oedematous and intensely congested in the non-destroyed areas. Unfortunately it was not possible to make further investigation of the histology of the organs affected.

\section{Summary}

Potassium permanganate, although one of the safest internal and external disinfectants in correct dilution, has toxic properties when used in concentration, and may even cause death, as has been shown by a review of the available literature. The fatal dose is not known, but it is seen from the reported case that 20 grams have proved fatal when injected through the urethral canal. Vaginal injection of a concentrated solution has also caused abortion. Consideration of its many uses emphasizes the necessity for its application in the correct dilution for the particular purpose ; otherwise, it may act as a severe irritant poison.

We are indebted to Dr. D. Dimitriou for some pathological details, and to the manager of the Cyprus and General Asbestos Company for permission to publish these findings.

\section{REFERENCES}

1 Popper: Klinik und Therapie Akuter Vergiftungen, Leipzig und Wien, 1933

2 Starkenstein, Rost, and Pohl: Toxicologie, Berlin, 1929.

3 Leschke: Die Wichtigsten Vergiftungen, München, 1933.

Taylor's Principles and Practice of Medical Jurisprudence, London, 1928, ii, 424.

- The Extra Pharmacopoeia, London, 1932, i, 545.

- Willimott and Gosden: British Medical Jonirnal, 1934, i, 1022.

7 Journ. Amer. Med. Assoc, 1913, i, 196. (Quoted from Squire's Companion to the B.P., 1916, p. 1098.)

- Dixon: Manual of Pharmacology, London, 1929, p. 415. 